\title{
Mechanisms underlying reduced fertility in anovular dairy cows
} Program, University of Florida, Gainesville, FL, USA

${ }^{2}$ Department of Veterinary Population Medicine, University of Minnesota, St. Paul, MN, USA

${ }^{3}$ Department of Animal Biosciences, University of Guelph, Guelph, Canada

$12{ }^{*}$ Corresponding author (J. E. P. Santos)

132250 Shealy Drive, Gainesville, FL 32611, USA

14 e-mail address: jepsantos@ufl.edu

15 Tel: +1 (352) 392-1958

16 Fax: +1 (352) 392-1931 


\section{ABSTRACT}

18 Resumption of ovulation after parturition is a coordinated process that involves recoupling

19 of the growth hormone (GH)/insulin-like growth factor (IGF)-1 axis in the liver, increase in

20 follicular development and steroidogenesis, and removal of negative feedback from estradiol in

21 the hypothalamus. Infectious and metabolic disorders associated with extensive negative energy

22 balance during early lactation disrupt this pathway and delay first ovulation postpartum.

23 Anovulatory conditions exert long-lasting detrimental effects on fertility in dairy cows including

24 the lack of spontaneous estrus, reduced pregnancy per artificial insemination (AI), and increased

25 risk of pregnancy loss. Concentrations of progesterone in anovular cows subjected to

26 synchronized programs for AI are insufficient to optimize follicular maturation, oocyte

27 competence and subsequent fertility to an insemination. Ovulation of first wave follicles, which

28 develop under low concentrations of progesterone, reduces embryo quality in the first week after

29 fertilization and pregnancy per AI (P/AI) in dairy cows. Although the specific mechanisms by

30 which anovulation and low concentrations of progesterone impair oocyte quality have not been

31 defined, studies with persistent follicles support the involvement of premature resumption of

32 meiosis and degradation of maternal RNA. Suboptimal concentrations of progesterone before

33 ovulation also increase the synthesis of $\mathrm{PGF}_{2 \alpha}$ in response to oxytocin during the subsequent

34 estrous cycle, which explains the greater incidence of short luteal phases after the first AI

35 postpartum in anovular cows compared with estrous cyclic herd mates. It is suggested that

36 increased spontaneous luteolysis early in the estrous cycle is one of the mechanisms that

37 contributes to early embryonic losses in anovular cows. Anovulation also leads to major shifts in

38 gene expression in elongated conceptuses during pre-implantation stages of pregnancy.

39 Transcripts involved with control of energy metabolism and DNA repair were downregulated 
40 whereas genes linked to apoptosis and autophagy were upregulated in Day 15 conceptuses

41 collected from anovular cows compared with estrous cyclic counterparts. Similar changes in

42 conceptus transcriptome were not observed in estrous cyclic cows induced to ovulate follicles

43 that grew under low and high concentrations of progesterone, indicating an effect of anovulation

44 on embryonic development that is not mediated solely by progesterone concentrations before

45 ovulation. Finally, risk factors for anovulation have direct effects on embryo development and

46 uterine receptivity to pregnancy that complement those determined by insufficient concentrations

47 of progesterone during follicular growth. One approach to minimize the impact of anovulation on

48 fertility is supplementation with progesterone during the antral stages of development of the

49 ovulatory follicle. It is suggested that a minimum of $2.0 \mathrm{ng} / \mathrm{mL}$ of progesterone is needed during

50 growth of the preovulatory follicle to achieve P/AI similar to that of cows growing the

51 preovulatory follicle during diestrus.

53 Keywords: anovular; conceptus; corpus luteum; disease; progesterone

\section{1. Introduction}

55 Reproductive efficiency plays a key role in the economic success of dairy herds, as it

56 influences milk production per day of calving interval and culling policies [1]. In spite of recent

57 advances related to management of reproduction with experiments achieving pregnancy per

58 artificial insemination (P/AI) in high-producing Holstein cows of 45 to 50\% [2-3], still less than

$5935 \%$ of the lactating dairy cows subjected to artificial insemination (AI) carry gestation to term

60 [4,5]. The establishment and maintenance of pregnancy relies on a delicate crosstalk among the

61 maternal hypothalamic-pituitary-gonadal axis, the endometrium, and the developing embryo. As

62 expected, physiological, metabolic, and pathological conditions that disrupt these pathways 
63 largely impair fertility. Extensive research supports the concept that anovulation is a major

64 impediment to reproductive performance in dairy cows. The proportion of cows that remain

65 anovular by the end of the voluntary waiting period varies among herds, genetic groups, and

66 management schemes, ranging between 5 and 40\% [6-8]. In addition to the lack of estrous

67 behavior that precludes insemination because of lack of estrous cyclicity, anovular cows

68 subjected to synchronization protocols consistently have reduced P/AI and increased risk of

69 pregnancy loss compared with estrous cyclic herd mates [5,7].

70 Although the detrimental effect of anovulation on reproduction is conspicuous, defining the

71 specific mechanisms contributing to the poor fertility observed in anovular dairy cows continues

72 to challenge researchers. The hallmark of anovulatory conditions is the absence of corpus luteum

73 (CL) and ensuing insufficient concentrations of progesterone during growth of the ovulatory

74 follicle, which reduces embryo quality in the first week after fertilization $[9,10]$, increases the

75 release of prostaglandin- $\mathrm{F}_{2 \alpha}\left(\mathbf{P G F}_{2 \alpha}\right)$ in response to oxytocin during the subsequent estrous cycle

$76[11,12]$, and decreases P/AI in lactating dairy cows [13]. On the other hand, some of the risk

77 factors for anovulation also have direct effects on fertility responses. Delayed resumption of

78 ovulation is associated with dystocia, extensive negative energy balance and loss of body

79 condition postpartum, as well as the occurrence of diseases during early lactation $[6-8,14]$. The

80 hormonal and metabolic milieus imposed by such circumstances have been shown to decrease

81 the frequency of luteinizing hormone ( $\mathbf{L H})$ pulses [15,16], impair follicular maturation and

82 oocyte competence [17-19], upregulate the expression of inflammatory mediators in the

83 endometrium [20], and impair conceptus elongation [21]. Therefore, strategies to improve

84 reproduction in high-producing dairy cows must combine therapies to increase fertility of 
ICAR S5R1-Santos

85 anovular cows that is coupled with adequate management during the transition period to promote

86 health and expedite resumption of ovulation postpartum.

\section{2. Insufficient concentrations of progesterone during follicular growth}

88 Decreased fertility in anovular cows subjected to timed AI programs is largely mediated by

89 insufficient concentrations of progesterone during growth of the ovulatory follicle. For instance,

90 P/AI did not differ between anovular cows and estrous cyclic herdmates without a functional CL

91 at the first injection of GnRH of the synchronization protocol [13]. As opposed to cows in

92 diestrus at the initiation of the synchronization protocol, anovular and estrous cyclic cows

93 without CL are induced to ovulate a first wave follicle at insemination, which develops

94 simultaneously with the CL under low concentrations of progesterone. The fact that the wave of

95 the ovulatory follicle had a greater impact on P/AI (i.e., P/AI in cows ovulating the $2^{\text {nd }}$ wave

96 follicle was greater than cows ovulating the $1^{\text {st }}$ wave follicle) than did estrous cyclicity (i.e. P/AI

97 in anovulatory cow was similar to that of estrous cyclic cows ovulating $1^{\text {st }}$ wave follicle),

98 suggests that the hormonal milieu during the final stages of follicular maturation is a major

99 determinant of poor fertility in anovular cows [13]. In fact, supplementation with progesterone

100 during growth of the ovulatory follicle improved embryo quality in cows induced to ovulate first

101 wave follicles [10] and restored P/AI in anovular cows at the initiation of the timed AI program

$102[3,22]$. Such findings support a causal role of progesterone during growth of the ovulatory

103 follicle affecting P/AI. Moreover, cows that initiated a resynchronization protocol without a CL

104 had reduced P/AI compared with cows with a CL and supplemental progesterone was effective at

105 reestablishing fertility in cows without a CL similar to that of cows in diestrus [22].

106 It remains unknown the ideal concentrations of progesterone during follicle growth to

107 optimize fertility in anovular cows or cows that lack a CL when the pre-ovulatory follicle is 
108 recruited for subsequent ovulation. Wiltbank et al. [23] clearly indicated the importance of high

109 concentrations of progesterone during the pre-ovulatory period coupled with very low

110 concentrations during proestrus. Their group showed that not only P/AI increased, but pregnancy

111 loss decreased (6.8 vs. 14.3\%) when cows had high compared with low progesterone

112 concentrations during the follicular wave that resulted in the ovulatory follicle [9]. Lactating

113 dairy cows in mid diestrus have concentrations of progesterone that are highly variable and

114 dynamic [23], but usually range from 3 to $6 \mathrm{ng} / \mathrm{mL}[3,11,22]$. Evidence from experiments in

115 which progesterone concentrations were manipulated pre-AI suggest that a minimum of 2.0 to

$1163.0 \mathrm{ng} / \mathrm{mL}$ are needed to achieve P/AI in anovular cows that resemble those of cows in diestrus

117 [22].

118 2.1. Effects of LH on oocyte quality and early embryo development

119 Despite the fact that bovine cumulus-oocyte complexes are responsive to progesterone [24],

120 intra-follicular concentrations are determined by steroidogenesis within the granulosa cells and

121 are approximately 10-fold greater than those measured in plasma during the first follicular wave

122 [25]. Therefore, the effects of low concentrations of progesterone in plasma on follicular

123 maturation and subsequent embryo development are likely mediated by changes in LH pulse

124 frequency rather than a direct impact on the follicle. Results from sheep and mice indicate that

125 progesterone depresses the release of GnRH via the kisspeptin/GPR54 system at the

126 hypothalamus [26,27]. In ewes, kisspeptin positive neurons also express progesterone receptor

127 [28], and supplementation with progesterone to ovariectomized ewes depressed the number of

128 neurons expressing mRNA for kisspeptin in the arcuate nucleus [28]. It is known that

129 progesterone depress LH pulse frequency in cattle [29] and low concentrations of progesterone

130 are associated with greater frequency of LH pulses during metestrus compared with diestrus [30]. 
131 Collectively, these data suggest that low concentrations of progesterone influence follicle and

132 oocyte development through increased secretion of $\mathrm{LH}$ that accelerates follicle growth and can

133 depress oocyte quality.

134 Throughout final stages of follicular development, oocytes remain arrested at the diplotene 135 stage of prophase I by inhibiting activation of the maturation promoting factor (MPF; [31]). The 136 pre-ovulatory surge of LH increases intracellular cyclic adenosine monophosphate (cAMP) in 137 the cumulus cells, leading to activation of protein kinase (PK) A type II and PKC, expression of 138 epidermal growth factor (EGF)-like factors, activation of mitogen-activated protein kinase 139 (MAPK), and disruption of the gap junctions between cumulus cells and the oocyte [32,33]. The 140 lack of communication between the oocyte and surrounding cells blocks cAMP transfer towards 141 the oocyte, which in combination with its hydrolysis by phosphodiesterase 3A (PDE3A), reduces 142 PKA activity and activates MPF. Resumption of meiosis is characterized by the breakdown of 143 the germinal vesicle and extrusion of the first polar body [34]. Another important characteristic 144 of oocyte maturation is the accumulation of maternal mRNA in order to provide templates for 145 protein synthesis before embryonic genome activation. Among other mechanisms, maternal 146 mRNA stored in the oocyte is protected from degradation through the binding of multifunctional 147 Y-box protein 2 (MSY2; [35]). This protection begins to be removed following the germinal 148 vesicle breakdown by MSY2 phosphorylation [36].

149 Changes in LH pulse frequency coupled with oocyte morphology and mRNA content have 150 not been evaluated in anovular dairy cows; however, it is possible that excessive exposure to LH 151 in cows with low concentrations of progesterone, via an extended period of increased LH pulse 152 frequency, advances the events associated with resumption of meiosis, thereby reducing oocyte 153 quality and subsequent embryo survival (Fig. 1). Oocytes from persistent follicles induced by 
154 sub-luteal concentrations of progesterone presented morphological signs of germinal vesicle

155 breakdown before ovulation [37], supposedly by long-term exposure to increased frequency of

156 LH pulses. This advancement in oocyte maturation possibly hastens the depletion of maternal

157 mRNA, increasing embryonic expression of cell death transcripts, and impairing development to

158 the blastocyst stage [38]. Using a heifer model, Schmitt et al. [39] showed that those induced to

159 have persistent follicles had reduced P/AI, which could be corrected with induction of a new

160 follicular wave by administration of GnRH. Extending the period of follicular dominance

161 reduced embryo quality on d 7 after AI [40] and decreased P/AI in cows inseminated following

162 spontaneous estrus [41] and in those subjected to timed AI programs [42]. In a similar manner,

163 ovulation of first wave follicles increased the proportion of degenerated embryos on Day 7 after

164 AI $[9,10]$, which was reversed by supplementation with progesterone during follicular growth $165[10]$.

\subsection{Effect of expression of estrus on subsequent fertility responses}

167 The growth of ovarian follicles and maturation of the enclosed oocyte are tightly controlled

168 processes that must occur simultaneously. Estradiol produced by the dominant follicle stimulates

169 estrous behavior and triggers a pre-ovulatory surge of LH to induce its own ovulation [27]. In

170 view of that, expression of estrus at $\mathrm{AI}$ is an indicator of follicular health and adequate timing of

171 the events involved with ovulation. It is interesting to note that anovulation [21] and insufficient

172 concentrations of progesterone during growth of the ovulatory follicle [3,22] only reduced P/AI

173 in cows not detected in estrus on the day of insemination (Fig. 2). Moreover, the reduction in

174 P/AI observed in cows that did not express estrous behavior at insemination was reversed by

175 progesterone supplementation [3,22]. A recent study in grazing dairy cows suggest that plasma

176 concentrations of anti-Müllerian hormone (AMH) are related with the interaction between 
177 progesterone concentration during follicular development and expression of estrus during timed

178 AI programs [43]. The proportion of cows detected in estrus at timed AI was influenced by $179 \mathrm{AMH}$ concentrations (low $\mathrm{AMH}=49.3 \%$, intermediate $\mathrm{AMH}=39.4 \%$, and high $\mathrm{AMH}=$ $18034.5 \%$ ). For cows with progesterone concentrations in plasma $<1.0 \mathrm{ng} / \mathrm{mL}$ at the initial $\mathrm{GnRH}$ 181 injection of the timed AI protocol, those with low concentrations of AMH had P/AI that was 182 greater than cows with intermediate or high AMH concentrations (40 vs. 25\%). No differences 183 in P/AI were detected between AMH categories in the presence of a functional CL, and P/AI 184 averaged $47 \%$.

\subsection{Legacy effects on $P G F_{2 \alpha}$ release and subsequent luteal lifespan}

During pre-implantation stages, bovine conceptuses must elongate rapidly and synthesize a

187 plethora of bioactive products that are essential for maintenance of pregnancy. Among such

188 molecules, the conceptus must secrete large amounts of interferon-tau (IFN- $\tau$ ) to inhibit the 189 pulsatile release of $\mathrm{PGF}_{2 \alpha}$ by the endometrium and prevent luteolysis $[44,45]$. Conceptuses grow 190 from a third of a millimeter to $25 \mathrm{~cm}$ between Days 11 and 17 of gestation, and length of the 191 conceptus is directly related to concentrations of IFN- $\tau$ in the uterine lumen [21]. Elongation and 192 consequently survival of the conceptus is dependent on histotroph secretion by the glandular 193 epithelium of the endometrium [44]. Adequate provision of nutrients, growth factors and 194 hormones in the histotroph stimulates cellular remodeling, proliferation, and differentiation in 195 the conceptus, which follows time-dependent events. It is well accepted that inability of 196 conceptus to develop properly or asynchrony between conceptus development and endometrial 197 maturation can potentially increase the risk of pregnancy loss because of the inability of a less 198 advanced conceptus to block the luteolytic cascade or because of early spontaneous luteolysis. 199 The incidence of short luteal phases (< 11 days) following timed AI is greater among anovular 
200 cows compared with estrous cyclic counterparts $[11,46]$. Similar to the effects on oocyte quality

201 and early embryo development, hastening of the luteolytic cascade is mediated by low

202 concentrations of progesterone during preovulatory follicular growth. The incidence of short

203 estrous cycles, defined as reinsemination on estrus between 5 and 17 days after a previous AI,

204 was greater for anovular and estrous cyclic cows that ovulated first wave follicles compared with

205 herdmates in diestrus at the first GnRH injection of the synchronization protocol [3,13].

206 Moreover, the incidence of short estrous cycles was reduced by supplementing progesterone to

207 cows without CL at the initiation of the timed AI program [3].

208 The mechanism by which exposure to low progesterone concentrations during follicle

209 growth affect luteal lifespan in the subsequent estrous cycle involves uterine responsiveness to

210 oxytocin. Endometrial expression of oxytocin receptors in ruminants is suppressed until mid-

211 diestrus [47,48], when progesterone downregulates its own receptors in the luminal epithelium

212 and superficial glands allowing for oxytocin to trigger the luteolytic cascade [47]. Cows with low

213 concentrations of progesterone during preovulatory follicle growth had an anticipated increase in

214 protein expression for estrogen receptor- $\alpha$ in the endometrium [11] and greater concentrations of

215 13,14-dihydro-15-keto $\mathrm{PGF}_{2 \alpha}$ (PGFM) in plasma following an oxytocin challenge in the

216 subsequent diestrus [11,12]. On the other hand, supplementing postpartum beef cows with a

217 progestin (i.e. norgestomet) during follicular growth increased the expression of progesterone

218 receptors [49,50] and downregulated oxytocin receptors in the endometrium on Day 5 after

219 ovulation compared with untreated controls [49]. In addition, some experiments have shown that

220 low concentrations of progesterone during the preceding estrous cycle accelerates pre-ovulatory

221 follicle growth [11,51], which can result in larger CL in the subsequent estrous cycle and greater

222 concentrations of progesterone. Perhaps, the combined low and high concentrations of 
223 progesterone during the preceding and subsequent estrous cycles, respectively, induce the

224 premature luteolytic signaling that leads to short estrous cycles in some cows.

\section{3. Effects of anovulation on conceptus biology and late embryonic/fetal mortality}

In addition to the detrimental effect on P/AI, previous studies indicate that anovulatory

227 conditions increase the risk of late embryonic and fetal mortality in lactating dairy cows

$228[5,13,23]$. As opposed to the effects on P/AI, however, pregnancy loss is mostly affected by

229 estrous cyclic status and not by concentrations of progesterone during growth of the ovulatory

230 follicle. In fact, the incidence of pregnancy loss between Days 30 and 53 of gestation was

231 greatest for anovular cows (15.0\%), intermediate for cyclic cows in diestrus at the initiation of

232 the synchronization protocol (13.5\%), and lowest for cyclic cows induced to ovulate first wave

233 follicles that develop under low progesterone concentrations [10.0\%; 13].

234 Recent work by our group with lactating dairy cows revealed major shifts in gene expression

235 in conceptuses cells from anovular cows [21]. These changes in conceptus transcriptome were

236 not observed in estrous cyclic cows with low concentrations of progesterone before AI [51].

237 Transcriptome analyses of Day 15 elongated conceptuses detected 500 transcripts affected by

238 estrous cyclicity of which 262 were upregulated and 238 were downregulated in anovular

239 compared with the referent estrous cyclic Holstein cows. Eighty-seven probesets were

240 upregulated in conceptuses from anovular cows in association with progression of conceptuses

241 from tubular to filamentous stages, reflecting the increase in the length of the trophectoderm in

242 anovular cows compared with estrous cyclic counterparts. Nevertheless, most of the

243 differentially expressed transcripts were not related to improved embryo development and may

244 explain the greater occurrence of pregnancy loss in anovular cows. Transcripts involved with

245 phosphatidylinositol/AKT signaling (IMPA1, IMPA2, PIP5K1A, and AKT2) were downregulated 
246 in conceptuses from anovular cows. Because phosphatidylinositol/AKT is a key downstream

247 mediator of insulin-like growth factor 1 (IGF-1) actions [52] and affects the mechanistic target

248 of rapamycin (mTOR) signaling, its downregulation might affect energy metabolism, cell

249 survival, proliferation and migration during establishment of gestation [53]. The transcripts

250 associated with DNA repair were also downregulated in response to anovulation, including

251 TOP1 and NBN which are required for embryo survival in mouse models [54-56]. Moreover, the

252 expression of transcripts involved with apoptosis (CASP6 and GSK3B) and autophagy (ATG4A,

253 MAP1LC3B, and LAMP1) were upregulated in conceptuses from anovular cows, which has been

254 associated with embryo mortality and termination of pregnancy [57]. It is interesting to note that

255 conceptus length and the concentrations of IFN- $\tau$ in the uterine flush fluid were greater for

256 anovular than estrous cyclic cows, providing no morphological evidence of poor embryonic

257 development in anovular cows for conceptuses that develop to Day 15 of gestation [21]. The

258 collective results from the transcriptome analysis pointed to differences in canonical pathways

259 related to apoptosis, 14-3-3 protein signaling, and autophagy, perhaps suggesting greater cellular

260 stress and the need to eliminate aberrant protein aggregates and malfunctioning organelles. Thus,

261 the aforementioned findings support the hypothesis that some of the detrimental effects of

262 anovulation on embryo survival, although already imprinted during the pre-implantation stages,

263 will be expressed later in gestation and provides biological support to explain the greater

264 incidence of later embryonic/fetal mortality in anovular cows [3,13,21].

265 Using a different model with nonlactating Holstein cows to study the role of progesterone on

266 conceptus biology, we showed that the transcriptome of Day 17 conceptus was not substantially

267 affected by low concentrations of progesterone during the development of the preovulatory

268 follicle [51]. Only nine probesets were affected by concentrations of progesterone during 
269 follicular growth. Among the differently expressed genes, transcripts involved with cell adhesion

270 (CD97), signal transduction and ion transport (P2RY1), cytoskeleton organization (CNN2),

271 glucose metabolism (PFKP), and embryo survival (CALCRL) were upregulated in conceptuses

272 collected from cows with low progesterone concentrations during follicular growth compared

273 with cows with high progesterone concentrations. Although progesterone mediates a large

274 portion of the effects of anovulation in reducing fertility in dairy cows [13], and sufficient

275 supplemental progesterone can restore P/AI [3,22] and reduce pregnancy loss in anovular dairy

276 cows [58], it is clear that the lesions caused by anovulation on conceptus cells are more complex

277 and not explained simply by the endocrine milieu during the pre- and periovulatory periods. A

278 major risk factor for anovulation is disease during the peripartum period [59], and cows that

279 suffered disease in early lactation had conceptuses with inflammation-like changes in the

280 transcriptome and up-regulation of major histocompatibility complex (MHC)-I heavy chain

281 BOLA gene [60]. Such changes suggest that these conceptus cells are less likely to escape

282 surveillance of the maternal immune system, thereby posing an increased risk for pregnancy loss $283[60]$.

\section{4. Risk factors for anovulation also have impact on fertility responses}

285 The transition from late gestation to early lactation is extremely challenging to high286 producing dairy cows. A sharp increase in nutrient requirement occurs with the onset of 287 lactation, which is not met by voluntary feed intake, leading to negative nutrient balance and 288 extensive mobilization of body reserves [61]. In spite of homeostatic controls and homeorhetic 289 adjustments that allow for partitioning of nutrients towards milk synthesis, 45 to $60 \%$ of dairy 290 cows across different levels of milk production, breeds, and management systems develop health 291 disorders postpartum [8,59,60]. Many of the events that affect cows in early lactation are known 
292 risk factors for anovulatory conditions, but metabolic and infectious diseases that are common in

293 the periparturient period have direct impacts on follicular maturation, embryo development, and

294 uterine environment [60]. Thus, this complex array of events in early lactation contribute to the

295 reduced fertility in dairy cows beyond simply delaying or preventing resumption of estrous

296 cyclicity This concept is supported by the observation that health disorders and anovulation have

297 additive effects on depressing fertility in lactating dairy cows [60].

\subsection{Negative nutrient balance and metabolic health during the transition period}

Energy balance in early lactation has been associated positively with reproductive success,

300 and cows that lose excessive body condition in the first weeks to two months postpartum have

301 delayed resumption of estrous cyclicity [7,62]. In a similar manner, dairy cows with elevated

302 concentrations of non-esterified fatty acids (NEFA) in serum $(\geq 0.7 \mathrm{mM})$ are more likely to

303 remain anovular by Day 49 postpartum [8]. The inclusion of saturated fatty acids into the culture

304 media induced apoptosis and necrosis of cumulus cells, impairing fertilization and early

305 embryonic development in vitro [63]. The concentrations of NEFA in the follicular fluid parallel

306 those observed in serum in dairy cows in early lactation [63], and increased lipomobilization

307 with the onset of lactation results not only in increased serum NEFA concentrations [64], but

308 also NEFA with more saturated fatty acids [64]. Therefore, it is plausible to suggest that

309 extensive lipolysis in early lactation not only influence the risk of anovulation, but it might also

310 alter the lipid composition of the follicular fluid which might imprint negative characteristics on

311 oocytes and granulosa cells from follicles that will ovulate during the breeding period.

312 Negative nutrient balance in early lactation influences dairy cows beyond the changes in

313 blood NEFA that can affect reproductive tissues. Insufficient caloric intake reduces

314 concentrations of insulin, which downregulates hepatic expression of GH receptor 1A and 
315 uncouples the GH/IGF-1 axis in dairy cows [65]. It is known that insulin and IGF-1 in early

316 lactation were linked with nutrient intake and energy balance, and cows that remain anovular are

317 known to have reduced concentrations of these metabolic hormones in early lactation [21]. The

318 low concentrations of IGF-1 in anovular cows might be the result of uncoupling of the GH-IGF

319 axis, which compromises follicular steroidogenesis [66] and seems to diminish sensitivity to LH

320 in ovarian follicles [67]. Furthermore, undernutrition and reductions in IGF-1 in early lactation

321 not only compromises resumption of ovulation, but it can have direct effects on the embryo. It

322 has been shown that increments in concentrations of IGF-1 with treatment with exogenous GH

323 stimulate conceptus development and conceptus-maternal tissues cross-talk though IFN- $\tau$, which

324 ultimately resulted in improved maintenance of pregnancy in lactating dairy cows [68].

325 Resumption of ovulation postpartum is affected by calcium homeostasis and cows with

326 subclinical hypocalcemia $(\leq 2.14 \mathrm{mM})$ during the first week postpartum are more likely to be

327 anovular at the end of the voluntary waiting period [8]. Hypocalcemia not only delayed estrous

328 cyclicity [8], but it also depressed pregnancy rate in dairy cows [69]. To a great extent, the

329 detrimental effects of hypocalcemia on fertility are likely mediated by the important role of

330 calcium for proper function of immune cells and the ensuing prevention of uterine and other

331 peripartum diseases. Induction of subclinical hypocalcemia reduced the percentage of

332 neutrophils undergoing phagocytosis and impaired oxidative burst in dairy cows [70]. Cows with

333 hypocalcemia in at least one of the first 3 days postpartum had greater risk of developing fever

334 and metritis [69]. Hypocalcemia exacerbates lipomobilization [69,70] because of reduced release

335 of pancreatic insulin [70] and reduced adipose tissue sensitivity to insulin induced by the high

336 parathyroid hormone concentration [71]. The negative effects of hypocalcemia on insulin might

337 further compromise the recoupling of the GH/IGF axis that is critical for follicular function and 
338 steroidogenesis $[65,66]$. Furthermore, hypocalcemia directly depress dry matter intake [70], the

339 main driving force influencing energy balance in dairy cows [59]. Collectively, the detrimental

340 effects of hypocalcemia on energy metabolism and innate immune function likely explain the

341 delay in estrous cyclicity postpartum and the increased risk of metabolic and inflammatory

342 diseases known to depress P/AI in dairy cows [59,60].

\section{3}

344

345

346

347

\subsection{Incidence of diseases postpartum}

Inflammatory and metabolic diseases are major factors that underlie anovulatory conditions in dairy cows. For instance, metritis, respiratory problems and indigestion increased the odds of cows remaining anovular by Day 49 postpartum by 2.4, 4.1, and 4.2-fold, respectively [8]. Disease increased the proportions of anovular cows from 18.9 to $26.6 \%$, and both disease and anovulation depressed P/AI in dairy cow (Fig. 3) [60]. Because diseases have such a profound impact on establishment and maintenance of pregnancy in dairy cattle $[59,60]$, and cows with health problems are more likely to be anovular, it is often difficult to clearly separate the exact mechanisms linking those perturbations with depressed fertility in dairy cows. It is interesting to note that disease and anovulation had additive effects depressing P/AI in dairy cows (Fig. 3), thereby suggesting that some of the mechanisms might be independent and complementary relative to the lesions that impair establishment and maintenance of pregnancy in cattle. Fertilization, development to the morula stage, conceptus biology, conceptus-maternal cross-talk, and maintenance of pregnancy to term were all influenced by disease in dairy cows. It is noteworthy that P/AI was depressed and pregnancy loss was increased similarly by disease regardless if cows received AI or embryo transfer [60]. Collectively, these data suggest that transferring an embryo is not capable of correcting the problem caused by disease and imply that 
360 the negative effects of disease, and potentially anovulation, are linked to the uterine environment

361 in which the embryo develops.

\section{5. Conclusions}

363 Anovulation is a complex condition that contributes to infertility in lactating dairy cattle by

364 affecting several processes that are essential for the establishment and maintenance of 365 pregnancy. The absence of a CL in anovular cows leads to insufficient concentrations of 366 progesterone during growth of the ovulatory follicle, which has been shown to impair subsequent 367 embryonic survival, shorten luteal lifespan around the time of maternal recognition of pregnancy, 368 and reduce P/AI. Changes in the transcriptome of elongated conceptuses indicate that the 369 detrimental effects of anovulation persist during the pre-implantation stages of gestation and are 370 likely implicated in the increased embryonic/fetal mortality observed in anovular cows. Recent 371 studies also indicate that anovulation and its predisposing factors have additive effects in 372 reducing fertility in lactating dairy cows. For that reason, reproductive management in dairy

373 herds should incorporate health and nutrition programs that minimize periparturient problems to 374 reduce the prevalence of anovulation when breeding starts. Programs should also focus on 375 methods to identify anovular cows that benefit from therapeutic interventions such as 376 progesterone supplementation and require manipulation of the estrous cycle such as timed AI 377 programs to ensure breeding at the proper time postpartum with adequate fertility.

\section{6. Acknowledgments}

379 Funding for experiments conducted by the authors and presented in this review was 380 provided by grants from the Southeast Milk Inc. Checkoff Program (Belleview, FL) and from the 381 National Institute of Food and Agriculture, United States Department of Agriculture award 
ICAR S5R1-Santos

382 number 2015-67015-23313.

383 
ICAR S52.R1 - Santos

\section{References}

[1] De Vries A. Economic value of pregnancy in dairy cattle. J Dairy Sci 2006;89:3876-85.

[2] Herlihy MM, Giordano JO, Souza AH, Ayres H, Ferreira RM, Keskin A, Nascimento AB, Guenther JN, Gaska JM, Kacuba SJ, Crowe MA, Butler ST, Wiltbank MC. Presynchronization with Double-Ovsynch improves fertility at first postpartum artificial insemination in lactating dairy cows. J Dairy Sci 2012;95:7003-14.

[3] Bisinotto RS, Ribeiro ES, Lima FS, Martinez N, Greco LF, Barbosa LF, et al. Targeted progesterone supplementation improves fertility in lactating dairy cows without a corpus luteum at the initiation of the timed artificial insemination protocol. J Dairy Sci 2013;96:2214-25.

[4] Norman HD, Wright JR, Hubbard SM, Miller RH, Hutchison JL. Reproductive status of Holstein and Jersey cows in the United States. J Dairy Sci 2009;92:3517-28.

[5] Santos JE, Thatcher WW, Chebel RC, Cerri RL, Galvão KN. The effect of embryonic death rates in cattle on the efficacy of estrus synchronization programs. Anim Reprod Sci 2004;82-83:513-35.

[6] Walsh RB, Kelton DF, Duffield TF, Leslie KE, Walton JS, LeBlanc SJ. Prevalence and risk factors for postpartum anovulatory condition in dairy cows. J Dairy Sci 2007;90:315-24.

[7] Santos JE, Rutigliano HM, Sa Filho MF. Risk factors for resumption of postpartum estrous cycles and embryonic survival in lactating dairy cows. Anim Reprod Sci 2009;110:207-21.

[8] Ribeiro ES, Lima FS, Greco LF, Bisinotto RS, Monteiro AP, Favoreto M, et al. Prevalence of periparturient diseases and effects on fertility of seasonally calving grazing dairy cows supplemented with concentrates. J Dairy Sci 2013;96:5682-97.

[9] Cunha AP, Guenther JN, Maroney MJ, Giordano JO, Nascimento AB, Bas S, et al. Effects of high vs. low progesterone concentrations during Ovsynch on double ovulation rate and pregnancies per AI in high producing dairy cows. J Dairy Sci 2008;91(Suppl. 1):246 (Abstr.).

[10] Rivera FA, Mendonca LG, Lopes G, Jr., Santos JE, Perez RV, Amstalden M, et al. Reduced progesterone concentration during growth of the first follicular wave affects embryo quality but has no effect on embryo survival post transfer in lactating dairy cows. Reproduction 2011;141:333-42.

[11] Cerri RL, Chebel RC, Rivera F, Narciso CD, Oliveira RA, Amstalden M, et al. Concentration of progesterone during the development of the ovulatory follicle: II. Ovarian and uterine responses. J Dairy Sci 2011;94:3352-65.

[12] Shaham-Albalancy A, Folman Y, Kaim M, Rosenberg M, Wolfenson D. Delayed effect of low progesterone concentrations on bovine uterine PGF(2alpha) secretion in the subsequent oestrous cycle. Reproduction 2001;122:643-8. 
[13] Bisinotto RS, Chebel RC, Santos JEP. Follicular wave of the ovulatory follicle and not cyclic status influences fertility of dairy cows. J Dairy Sci 2010;93:3578-87.

[14] Wiltbank MC, Gumen A, Sartori R. Physiological classification of anovulatory conditions in cattle. Theriogenology 2002;57:21-52.

[15] Schillo KK. Effects of dietary energy on control of luteinizing hormone secretion in cattle and sheep. J Anim Sci 1992;70:1271-82.

[16] Kadokawa H, Blache D, Martin GB. Plasma leptin concentrations correlate with luteinizing hormone secretion in early postpartum Holstein cows. J Dairy Sci 2006;89:3020-7.

[17] Cetica P, Pintos L, Dalvit G, Beconi M. Activity of key enzymes involved in glucose and triglyceride catabolism during bovine oocyte maturation in vitro. Reproduction 2002; $124: 675-81$.

[18] Leroy JL, Vanholder T, Delanghe JR, Opsomer G, Van Soom A, Bols PE, et al. Metabolic changes in follicular fluid of the dominant follicle in high-yielding dairy cows early postpartum. Theriogenology 2004;62:1131-43.

[19] Leroy JL, Vanholder T, Opsomer G, Van Soom A, de Kruif A. The in vitro development of bovine oocytes after maturation in glucose and beta-hydroxybutyrate concentrations associated with negative energy balance in dairy cows. Reprod Domest Anim 2006;41:11923.

[20] Wathes DC, Cheng Z, Chowdhury W, Fenwick MA, Fitzpatrick R, Morris DG, et al. Negative energy balance alters global gene expression and immune responses in the uterus of postpartum dairy cows. Physiol Genomics 2009;39:1-13.

[21] Ribeiro ES, Monteiro APA, Bisinotto RS, Lima FS, Greco LF, Ealy AD, Thatcher WW, Santos JEP. Conceptus development and transcriptome at preimplantation stages in lactating dairy cows of distinct genetic groups and estrous cyclic statuses. J Dairy Sci 2016; 99: (submitted in review).

[22] Bisinotto RS, Castro LO, Pansani MB, Narciso CD, Martinez N, Sinedino LD, et al. Progesterone supplementation to lactating dairy cows without a corpus luteum at initiation of the Ovsynch protocol. J Dairy Sci 2015;98:2515-28.

[23] Wiltbank MC, Souza AH, Carvalho PD, Cunha AP, Giordano JO, Fricke PM, Baez GM, Diskin MG. Physiological and practical effects of progesterone on reproduction in dairy cattle. Animal 2014;8(Suppl. 1):70-81.

[24] Aparicio IM, Garcia-Herreros M, O'Shea LC, Hensey C, Lonergan P, Fair T. Expression, regulation, and function of progesterone receptors in bovine cumulus oocyte complexes during in vitro maturation. Biol Reprod 2011;84:910-21.

[25] Badinga L, Driancourt MA, Savio JD, Wolfenson D, Drost M, Sota DL, et al. Endocrine and ovarian responses associated with the first-wave dominant follicle in cattle. Biol Reprod 1992;47:871-83. 
ICAR S52.R1 - Santos

[26] Dungan HM, Clifton DK, Steiner RA. Minireview: Kisspeptin neurons as central processors in the regulation of gonadotropin-releasing hormone secretion. Endocrinology 2006; 147:1154-8.

[27] Clarke IJ, Pompolo S. Synthesis and secretion of GnRH. Anim Reprod Sci 2005;88:29-55.

[28] Smith JT, Clay CM, Caraty A, Clarke IJ. KiSS-1 messenger ribonucleic acid expression in the hypothalamus of the ewe is regulated by sex steroids and season. Endocrinology 2007;148:1150-7.

[29] Kinder JE, Kojima FN, Bergfeld EGM, Wehrman ME, Fike KE. Progestin and estrogen regulation of pulsatile $\mathrm{LH}$ release and development of persistent ovarian follicles in cattle. $\mathrm{J}$ Anim Sci 1996;74:1424-40.

[30] Endo N, Nagai K, Tanaka T, Kamomae H. Comparison between lactating and non-lactating dairy cows on follicular growth and corpus luteum development, and endocrine patterns of ovarian steroids and luteinizing hormone in the estrous cycles. Anim Reprod Sci 2012;134:112-8.

[31] Mehlmann LM. Stops and starts in mammalian oocytes: Recent advances in understanding the regulation of meiotic arrest and oocyte maturation. Reproduction 2005;130:791-9.

[32] Zhang M, Ouyang H, Xia G. The signal pathway of gonadotrophins-induced mammalian oocyte meiotic resumption. Mol Hum Reprod 2009;15:399-409.

[33] Tripathi A, Kumar KV, Chaube SK. Meiotic cell cycle arrest in mammalian oocytes. J Cell Physiol 2010;223:592-600.

[34] Dekel N. Molecular control of meiosis. Trends Endocrinol Metab 1995;6:165-9.

[35] Yu J, Deng M, Medvedev S, Yang J, Hecht NB, Schultz RM. Transgenic RNAi-mediated reduction of MSY2 in mouse oocytes results in reduced fertility. Dev Biol 2004;268:195206.

[36] Yu J, Hecht NB, Schultz RM. Expression of MSY2 in mouse oocytes and preimplantation embryos. Biol Reprod 2001;65:1260-70.

[37] Revah I, Butler WR. Prolonged dominance of follicles and reduced viability of bovine oocytes. J Reprod Fertil 1996;106:39-47.

[38] Meirelles FV, Caetano AR, Watanabe YF, Ripamonte P, Carambula SF, Merighe GK, et al. Genome activation and developmental block in bovine embryos. Anim Reprod Sci 2004;8283:13-20.

[39] Schmitt EJ, Drost M, Diaz T, Roomes C, Thatcher WW. Effect of a gonadotropin-releasing hormone agonist on follicle recruitment and pregnancy rate in cattle. J Anim Sci 1996;74:154-61. 
ICAR S52.R1 - Santos

491

492

493

494

495

496

497

498

499

500

501

502

503

504

505

506

507

508

509

510

511

512

513

514

515

516

517

518

519

520

521

522

523

524

525

526

[40] Cerri RL, Rutigliano HM, Chebel RC, Santos JEP. Period of dominance of the ovulatory follicle influences embryo quality in lactating dairy cows. Reproduction 2009;137:813-23.

[41] Bleach EC, Glencross RG, Knight PG. Association between ovarian follicle development and pregnancy rates in dairy cows undergoing spontaneous oestrous cycles. Reproduction 2004;127:621-9.

[42] Santos JE, Narciso CD, Rivera F, Thatcher WW, Chebel RC. Effect of reducing the period of follicle dominance in a timed artificial insemination protocol on reproduction of dairy cows. J Dairy Sci 2010;93:2976-88.

[43] Ribeiro ES, Bisinotto RS, Lima FS, Greco LF, Morrison A, Kumar A, et al. Plasma antiMüllerian hormone in adult dairy cows and associations with fertility. J Dairy Sci 2014;97:6888-900.

[44] Bazer FW, Burghardt RC, Johnson GA, Spencer TE, Wu G. Interferons and progesterone for establishment and maintenance of pregnancy: Interactions among novel cell signaling pathways. Biol Reprod 2008;8:179-211.

[45] Thatcher WW, Hansen PJ, Gross TS, Helmer SD, Plante C, Bazer FW. Antiluteolytic effects of bovine trophoblast protein-1. J Reprod Fertil Suppl 1989;37:91-9.

[46] Gümen A, Guenther JN, Wiltbank MC. Follicular size and response to Ovsynch versus detection of estrus in anovular and ovular lactating dairy cows. J Dairy Sci 2003;86:318494.

[47] McCracken JA, Custer EE, Lamsa JC. Luteolysis: A neuroendocrine-mediated event. Physiol Rev 1999;79:263-323.

[48] Robinson RS, Mann GE, Lamming GE, Wathes DC. Expression of oxytocin, oestrogen and progesterone receptors in uterine biopsy samples throughout the oestrous cycle and early pregnancy in cows. Reproduction 2001;122:965-79.

[49] Zollers WG, Jr., Garverick HA, Smith MF, Moffatt RJ, Salfen BE, Youngquist RS. Concentrations of progesterone and oxytocin receptors in endometrium of postpartum cows expected to have a short or normal oestrous cycle. J Reprod Fertil 1993;97:329-37.

[50] Sá Filho O, Guerra D, Vasconcelos J. Endometrial gene expression of estradiol, progesterone, and oxytocin receptors in anestrous Bos indicus cows treated with progesterone. J Dairy Sci 2009;92(E-Suppl. 1):441 (Abstr.).

[51] Bisinotto RS, Ribeiro ES, Greco LF, Taylor-Rodriguez D, McCoski SR, Ealy AD, Ayres H, Lima FS, Martinez N, Thatcher, WW, Santos JEP. Effects of follicular wave and progesterone concentrations during growth of the ovulatory follicle on conceptus development and endometrial transcriptome in dairy cows. Biol Reprod, submitted.

[52] Siddle K. Signaling by insulin and IGF receptors: Supporting acts and new players. J Mol Endocrinol 2011;47:R1-10. 
[53] Kim J, Erikson DW, Burghardt RC, Spencer TE, Wu G, Bayless KJ, et al. Secreted phosphoprotein 1 binds integrins to initiate multiple cell signaling pathways, including FRAP1/mTOR, to support attachment and force-generated migration of trophectoderm cells. Matrix Biol 2010;29:369-82.

[54] Morham SG, Kluckman KD, Voulomanos N, Smithies O. Targeted disruption of the mouse topoisomerase I gene by camptothecin selection. Mol Cell Biol 1996;16:6804-9.

[55] Zhu J, Petersen S, Tessarollo L, Nussenzweig A. Targeted disruption of the nijmegen breakage syndrome gene NBS1 leads to early embryonic lethality in mice. Curr Biol 2001;11:105-9.

[56] Dumon-Jones V, Frappart PO, Tong WM, Sajithlal G, Hulla W, Schmid G, et al. Nbn heterozygosity renders mice susceptible to tumor formation and ionizing radiation-induced tumorigenesis. Cancer Res 2003;63:7263-9.

[57] Toder V, Carp H, Fein A, Torchinsky A. The role of pro- and anti-apoptotic molecular interactions in embryonic maldevelopment. Am J Reprod Immunol 2002;48:235-44.

[58] Bisinotto RS, Lean IJ, Thatcher WW, Santos JEP. Meta-analysis of progesterone supplementation during timed artificial insemination programs in dairy cows. J Dairy Sci 2015;98:2472-87

[59] Santos JE, Bisinotto RS, Ribeiro ES, Lima FS, Greco LF, Staples CR, et al. Applying nutrition and physiology to improve reproduction in dairy cattle. Soc Reprod Fertil Suppl 2010;67:387-403.

[60] Ribeiro, ES, Gomes GC, Greco LF, Cerri RLA, Vieira-Neto A, Monteiro Jr PLJ, Lima FS, Bisinotto RS, Thatcher WW, Santos JEP. Carryover impact of postpartum inflammatory diseases on developmental biology and fertility in lactating dairy cows. J Dairy Sci 2016; 99: doi: $10.3168 /$ jds.2015-10337.

[61] Bell AW. Regulation of organic nutrient metabolism during transition from late pregnancy to early lactation. J Anim Sci 1995;73:2804-19.

[62] Butler WR. Energy balance relationships with follicular development, ovulation and fertility in postpartum dairy cows. Livest Prod Sci 2003;88: 211-8.

[63] Leroy JL, Vanholder T, Mateusen B, Christophe A, Opsomer G, de Kruif A, et al. Nonesterified fatty acids in follicular fluid of dairy cows and their effect on developmental capacity of bovine oocytes in vitro. Reproduction 2005;130:485-95.

[64] Contreras GA, O'Boyle NJ, Herdt TH, Sordillo LM. Lipomobilization in periparturient dairy cows influences the composition of plasma nonesterified fatty acids and leukocyte phospholipid fatty acids. J Dairy Sci 2010;93:2508-16.

[65] Butler ST, Marr AL, Pelton SH, Radcliff RP, Lucy MC, Butler WR. Insulin restores GH responsiveness during lactation-induced negative energy balance in dairy cattle: Effects on expression of IGF-I and GH receptor 1A. J Endocrinol 2003;176:205-17. 
ICAR S52.R1 - Santos

564

565

566

567

568

569

570

571

572

573

574

575

576

577

578

579

580

581

582

583
[66] Butler ST, Pelton SH, Butler WR. Insulin increases 17 beta-estradiol production by the dominant follicle of the first postpartum follicle wave in dairy cows. Reproduction 2004;127:537-45.

[67] Lucy MC, Beck J, Staples CR, Head HH, De La Sota RL, Thatcher WW. Follicular dynamics, plasma metabolites, hormones and insulin-like growth factor I (IGF-I) in lactating cows with positive or negative energy balance during the preovulatory period. Reprod Nutr Dev 1992;32:331-41.

[68] Ribeiro ES, Bruno RG, Farias AM, Hernandez-Rivera JA, Gomes GC, Surjus R, et al. Low doses of bovine somatotropin enhance conceptus development and fertility in lactating dairy cows. Biol Reprod 2014;90:10,1-12.

[69] Martinez N, Risco CA, Lima FS, Bisinotto RS, Greco LF, Ribeiro ES, et al. Evaluation of peripartal calcium status, energetic profile, and neutrophil function in dairy cows at low or high risk of developing uterine disease. J Dairy Sci 2012;95:7158-72.

[70] Martinez N, Sinedino LD, Bisinotto RS, Ribeiro ES, Gomes GC, Lima FS, et al. Effect of induced subclinical hypocalcemia on physiological responses and neutrophil function in dairy cows. J Dairy Sci 2014;97:874-87.

[71] Chang E, Donkin SS, Teegarden D. Parathyroid hormone suppresses insulin signaling in adipocytes. Mol Cel End 2009;307:77-82. 

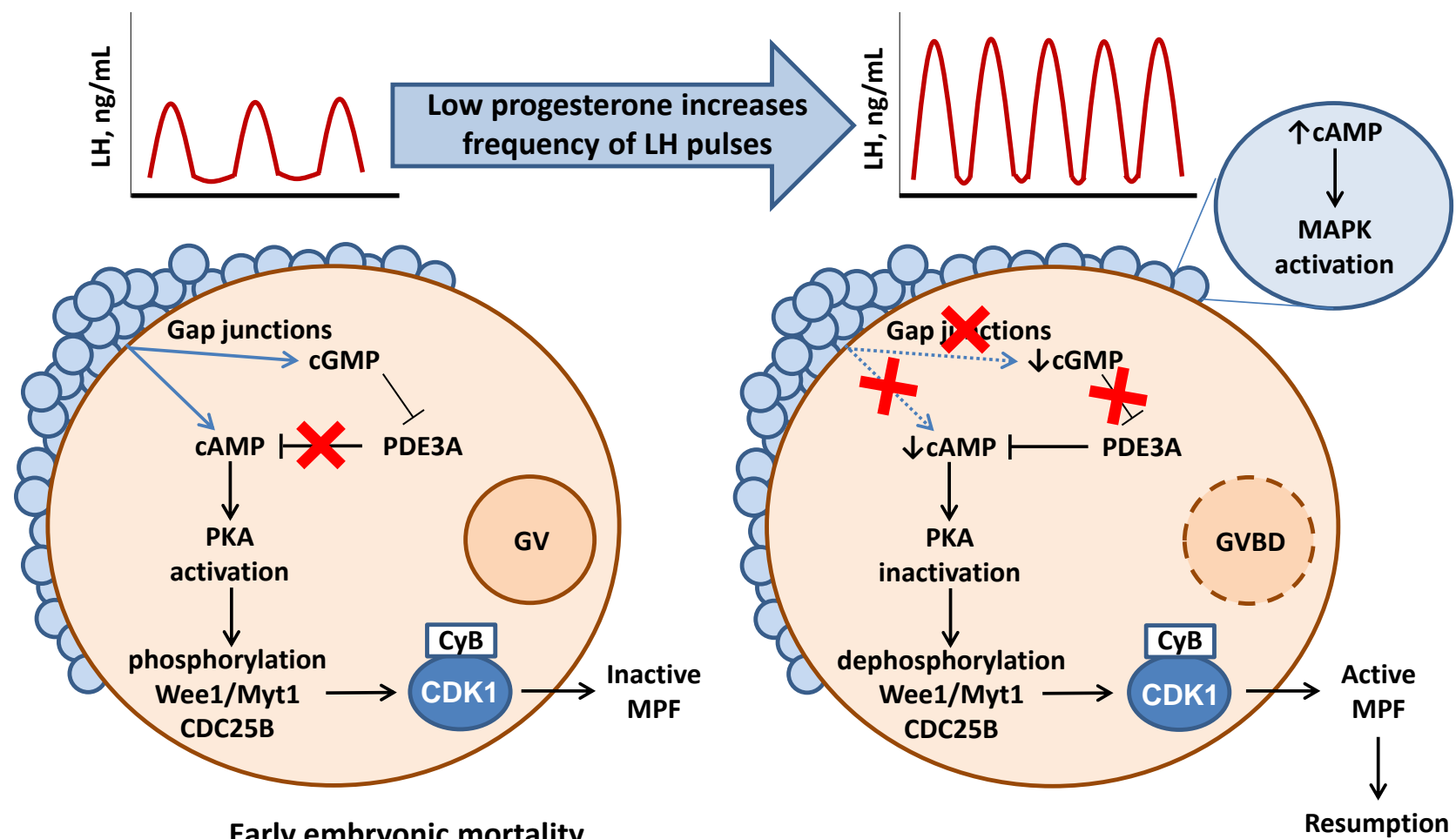

Early embryonic mortality
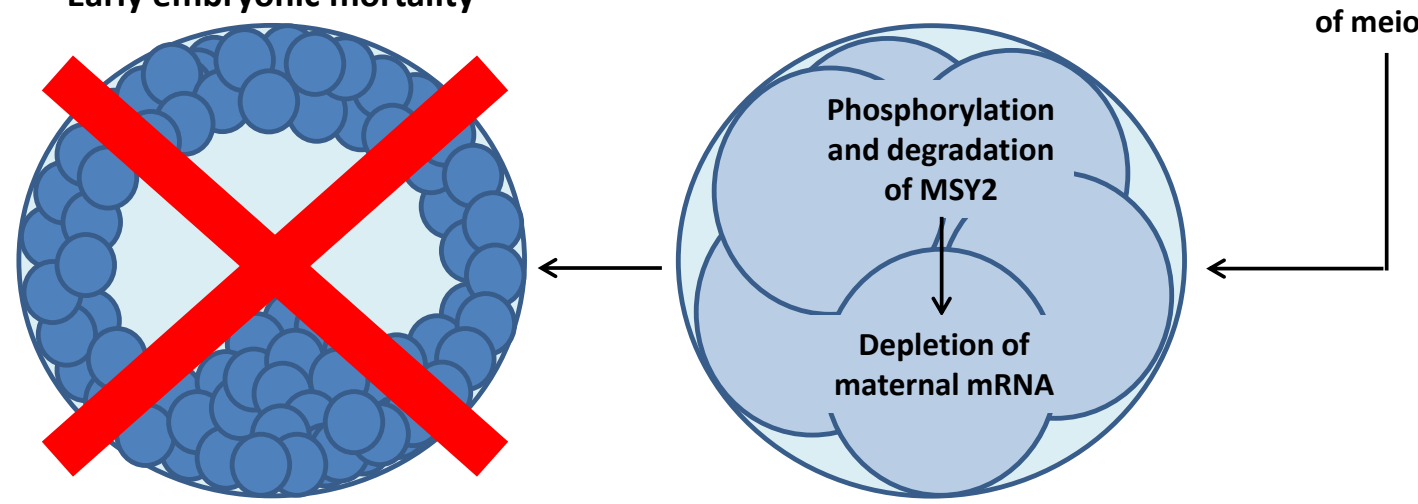

Fig. 1. Hypothetical model of the effects of elevated luteinizing hormone (LH) pulse frequency on follicle and oocyte maturation and subsequent embryo development. Before the preovulatory surge of $\mathrm{LH}$, the oocyte remains arrested at the diplotene stage of prophase I. Gap junctions allow for the transport of cyclic adenosine monophosphate (cAMP) and cyclic guanosine 3',5' monophosphate (cGMP) from cumulus cells to the oocyte, and cGMP inhibits the hydrolysis of cAMP by phosphodiesterase 3A (PDE3A). Elevated concentrations of cAMP within the oocyte activates protein kinase A (PKA), which 
ICAR S52.R1 - Santos

phosphorylates Wee1/Myt1, CDC25B, and cyclin-dependent kinase 1 (CDK1), thereby, inactivating the maturation promoting factor (MPF). Under low concentrations of 595 progesterone, the frequency of LH pulses increases, which in turn increases cAMP 596 production via adenylate cyclase in cumulus cells, thereby activating PKA type II and 597 protein kinase $\mathrm{C}(\mathrm{PKC})$. The actions of PKA and PKC induce epidermal growth factor 598 (EGF) like factors that activates mitogen-activated protein kinase (MAPK). This cascade of 599 events culminates with the disruption of gap junctions between cumulus cells and the 600 oocyte, blocking the transfer of cAMP and cGMP. The low cGMP favors hydrolysis of 601 cAMP by PDE3A, therefore, further reducing cAMP, which causes activation of MPF. 602 Hastening oocyte maturation results in germinal vesicle (GV) breakdown (GVBD), which 603 might be accompanied by removal of multifunctional Y-box protein 2 (MSY2) from stored 604 messenger ribonucleic acid (mRNA) and premature depletion of maternal RNA in the 605 oocyte, all of which are associated with reduced embryo quality and embryonic mortality 606 before the elongation of the blastocyst.

607 


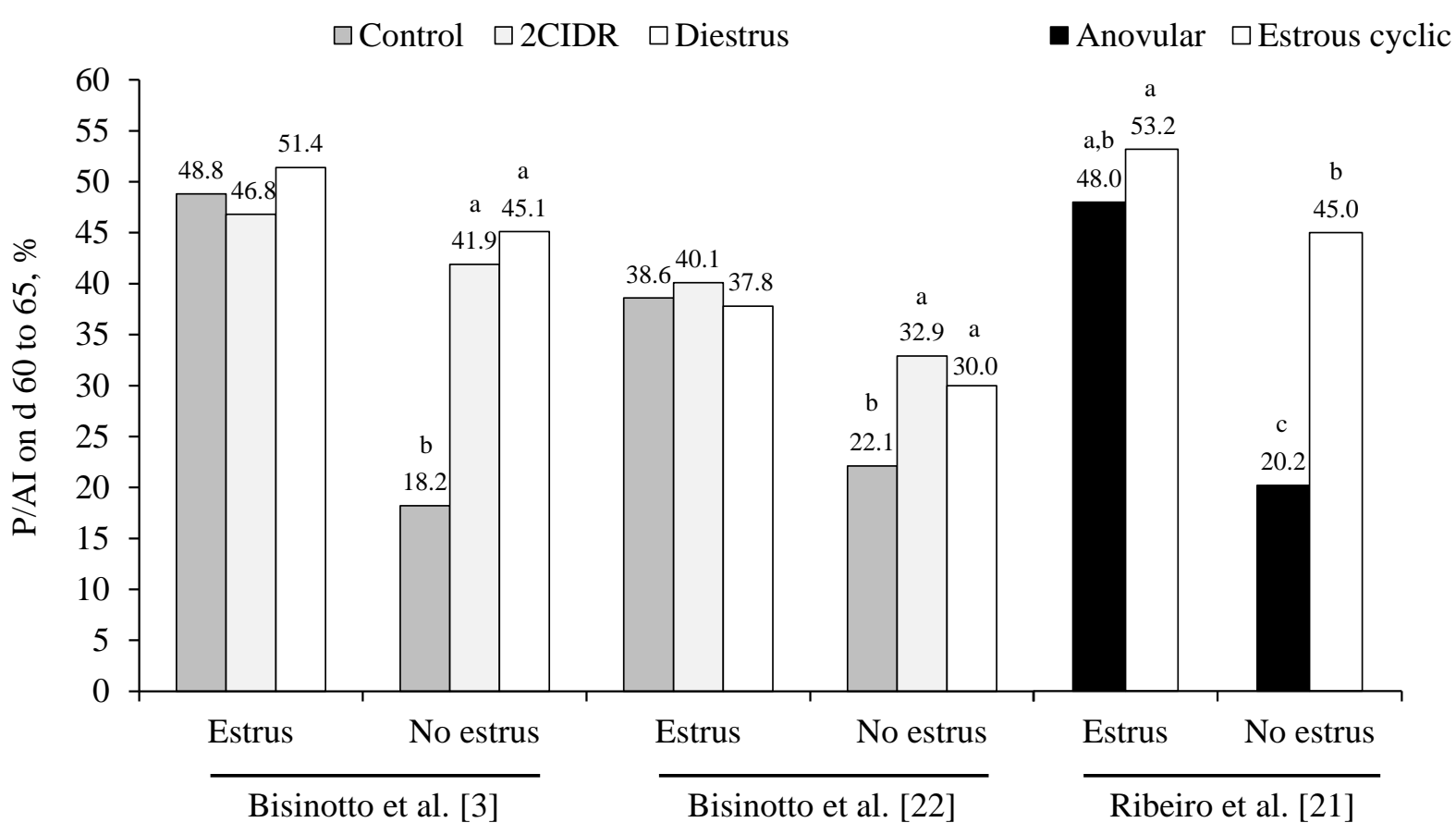

609 Fig. 2. Interaction among estrous cyclic status, concentration of progesterone during follicular

610 growth, and expression of estrus behavior at insemination on pregnancy per AI (P/AI) in 611 lactating dairy cows $[3,21,22]$. Cows were evaluated for presence of a corpus luteum (CL) 612 and those without CL were randomly assigned to receive no additional treatment or two 613 controlled-internal drug release (CIDR) containing progesterone. In Bisinotto et al [3,21] 614 supplementing progesterone using two intravaginal inserts reestablished P/AI in anovular 615 cows similar to that of cows in diestrus; however, the depression in P/AI caused by 616 anovulation was observed only in cows that did not display estrus on the day of timed AI.

617 Similarly, results from Ribeiro et al. [21] reiterate that the depression in fertility observed in 618 anovular compared with estrous cyclic cows is observed primarily in those that do not show 619 signs of estrus on the day of timed AI. ${ }^{\text {a,b,c }}$ Within study, proportions with different $620 \quad$ superscripts differ $(P<0.05)$. 


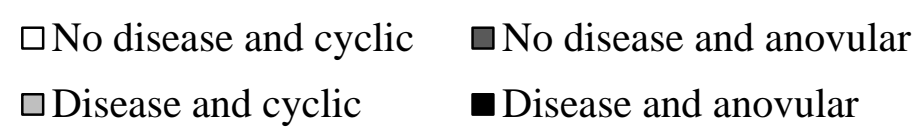

624 Fig. 3. Proportion of dairy cows pregnant on Day 32 after AI according to incidence of diseases 625 and estrous cyclicity before first insemination postpartum. Effect of disease $(P<0.01)$, 626 anovulation $(P<0.01)$, interaction between disease and anovulation $(P=0.70)$, and the 627 additive effect of disease and anovulation $(P<0.01)$. Disease and anovulation depressed 628 pregnancy on Day 32 and their effects were additive. Data from Ribeiro et al. [60].

629

630 